\title{
A Lumpy Bumpy Liver
}

\author{
Sunil V. Pawara, b, Vinay G. Zanwara, Samit S. Jain ${ }^{\mathrm{a}}$, \\ Pravin M. Rathi ${ }^{\mathrm{a}}$
}

\section{To the Editor}

A 40-year-old male patient presented with distension of abdomen since last 4 years. The distension was progressive and more in upper abdomen. He also developed umbilical hernia since 1 year. There was no jaundice or bleeding. On examination, massive hepatomegaly till right iliac fossa with multiple nodular swellings was felt. The computed tomography of abdomen showed hepatomegaly of $36 \mathrm{~cm}$ in size reaching up to pelvis (Fig. 1a). There were multiple variable sized non-enhancing hypodense cystic lesions seen in liver. A $3.4 \times 3.5 \mathrm{~cm}$ defect was seen in anterior abdominal wall in umbilical region with liver cysts as its content (Fig. 1b). Right kidney was seen in midline in the pelvis facing posteriorly. Both kidneys were enlarged with irregular lobulated contour with cystic lesions (Fig. 1c). The free fluid is seen in abdomen and pelvis. This is a case of polycystic liver and kidney disease with portal hypertension with ascites. Ultrasonography of the family members were normal. The patient was started on salt restricted diet and diuretics. The umbilical hernia was reduced and abdominal binder was applied.

The polycystic liver disease occurs as an extra-renal or- gan involvement in polycystic kidney disease. Rarely its presentation can be isolated. The cystic transformation of liver is secondary to ductal plate malformation and abnormal fluid secretion by cholangiocytes [1]. This can be managed with medications and genetic counseling. The surgical options are fenestration but recurrence is high, segmental hepatic resection if the cysts are localized and liver transplantation with or without kidney transplantation [2].

\section{Conflict of Interest}

There are no conflicts of interest of any authors.

\section{References}

1. Chandok N. Polycystic liver disease: a clinical review. Ann Hepatol. 2012;11(6):819-826.

2. Gevers TJ, Drenth JP. Diagnosis and management of polycystic liver disease. Nat Rev Gastroenterol Hepatol. 2013;10(2):101-108.

aDepartment of Gastroenterology, 7th Floor OPD Building, Topiwala National Medical College and Bai Yamunabai Laxman Nair Hospital, Mumbai Central, Mumbai, Maharashtra, India

${ }^{\mathrm{b}}$ Corresponding Author: Sunil Pawar, Department of Gastroenterology, 7th Floor OPD Building, Topiwala National Medical College and Bai Yamunaba Laxman Nair Hospital, Dr. Anandrao Nair Road, Mumbai Central, Mumbai, Maharashtra, India. Email: svpnavodaya@gmail.com

doi: http://dx.doi.org/10.14740/gr676w

Articles (C) The authors | Journal compilation (C) Gastroenterol Res and Elmer Press Inc ${ }^{\mathrm{TM}}$ | www.gastrores.org

This is an open-access article distributed under the terms of the Creative Commons Attribution License, which permits unrestricted use, distribution, and reproduction in any medium, provided the original work is properly cited 


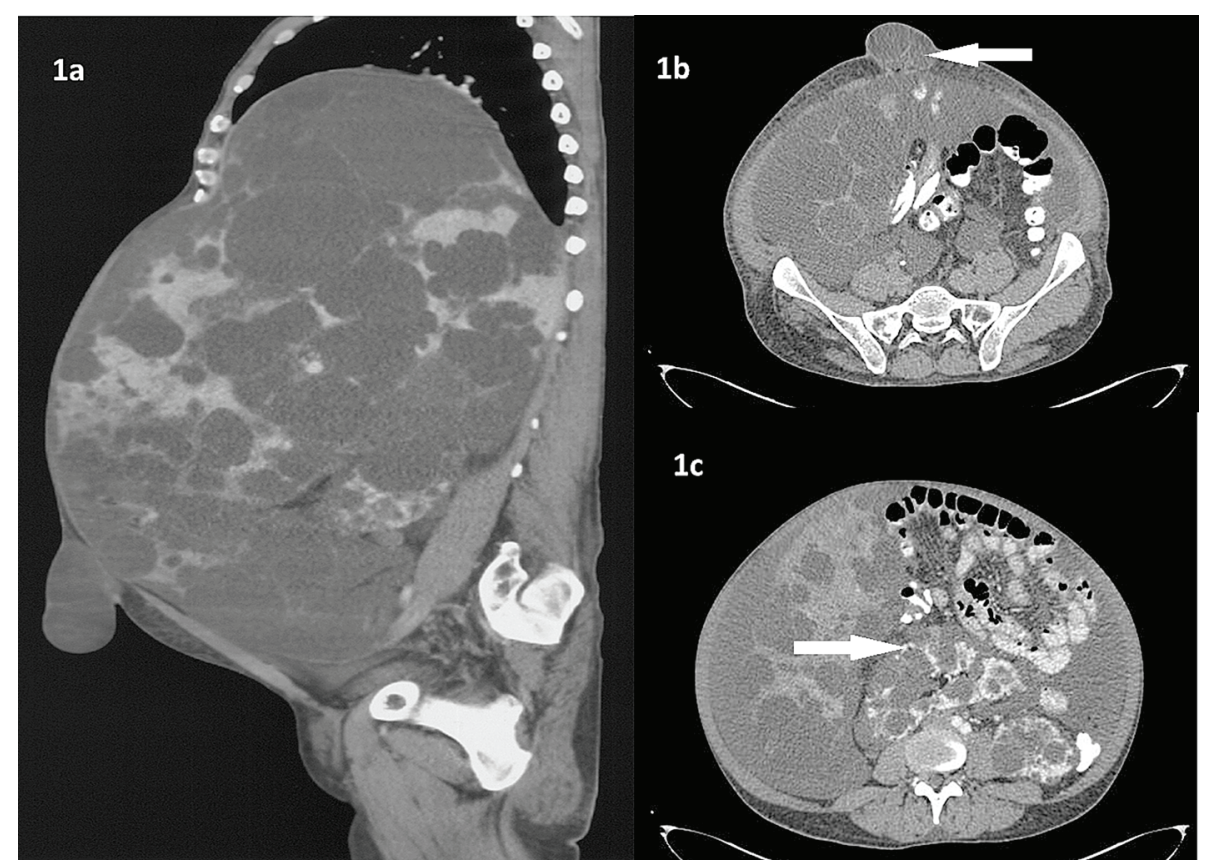

Figure 1. (a) Massive hepatomegaly with cystic lesions with umbilical hernia. (b) Umbilical hernia with hepatic cyst as its content. (c) Bilateral kidneys showing irregular lobulated contour with cystic lesions. Also note malrotation of right kidney. 